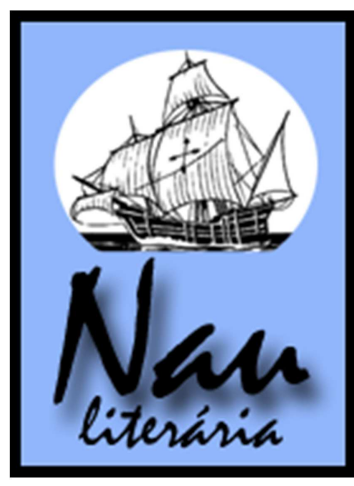

A memória e a escrita em Mia Couto e Graciliano Ramos: das fulgurações da utopia à visão trágica da realidade

\title{
Andrea Trench de Castro*
}

Resumo: Pretendemos traçar uma análise comparativa entre os romances Terra sonâmbula, de Mia Couto e São Bernardo, de Graciliano Ramos, tendo em vista a perspectiva do sujeito rememorante que se desenvolve em ambas as narrativas, a fim de mostrar como a memória exerce um papel estruturador e como os projetos de escrita que se entretecem nas narrativas podem apontar para diferentes interpretações das obras, considerando as fulgurações da utopia que têm lugar no texto de Mia Couto, e, por outro lado, a visão trágica que predomina no romance brasileiro.

Palavras-chave: Mia Couto; Graciliano Ramos; escritas da memória; utopia; trágico.

\begin{abstract}
This paper intends to draw a comparative analysis between the novels Terra Sonâmbula, by Mia Couto, and São Bernardo, by Graciliano Ramos, considering the perspective of the individual of remembrance that is developed in both narratives, in order to show how memory plays a structuring role and how the writing projects that blend themselves in the narratives can point to different interpretations of the works, taking into account the flashes of utopia that take place in Mia Couto's text, and, on the other hand, the tragic vision that prevails in the Brazilian novel.
\end{abstract}

Keywords: Mia Couto; Graciliano Ramos; writings of the memory; utopia; tragic.

Inserindo-nos no campo dos estudos comparados de literaturas de língua portuguesa, e buscando apontar parelelos existentes entre escritores e obras das literaturas brasileira e africana, pretendemos revelar neste artigo algumas convergências e divergências entre dois romances que se constroem a partir da presença significativa de sujeitos rememorantes (AUERBACH, 1998, p. 490), que empreendem uma busca consubstanciada no projeto de escrita: os romances São Bernardo, de Graciliano Ramos, e Terra Sonâmbula, de Mia Couto.

As escritas da memória, inscritas em diversos contextos socioculturais e históricos, pautam-se pela busca de reconstrução de identidades esfaceladas diante de contextos dolorosos, traumáticos e de perda. Assim, o preenchimento das lacunas existentes através do processo da rememoração efetua-se por meio da e na escrita, na qual a memória pode ser

\footnotetext{
Graduada em Letras Português-Linguística pela Universidade de São Paulo. Mestranda do programa de Estudos Comparados de Literaturas de Língua Portuguesa. Investiga relações literárias na formação e ascensão do romance em Portugal e França, século XIX. Interessa-se pelas articulações literárias entre países de expressão portuguesa.
} 
pensada como uma prática de intermediação entre expressões individuais e coletivas de identidade.

Assim, nos textos em questão, pode-se verificar que a memória exerce um papel estruturador: acompanha-se nos romances o desenvolver de personagens que através da rememoração constituem sua identidade e afirmam seus anseios em busca de conhecer e, sobretudo, revelar. O sujeito rememorante, que imerge em seu mundo interior para buscar respostas às suas inquietudes e para rever seu passado numa perspectiva subjetiva é constitutivo do romance moderno (cf. AUERBACH, 1998, p. 483):

Pois dentro de nós realiza-se incessantemente um processo de formulação e de interpretação, cujo objeto somos nós mesmos: a nossa vida, com passado, presente e futuro; o meio que nos rodeia; o mundo em que vivemos, tudo isso tentamos incessantemente interpretar e ordenar, de tal forma que ganhe para nós uma forma de conjunto, a qual, evidentemente, segundo sejamos obrigados, inclinados e capazes de assimilar novas experiências se nos apresentam, modifica-se constantemente de forma mais rápida ou mais lenta, mais ou menos radical (AUERBACH, 1998, p. 494).

No romance de Graciliano Ramos, a busca de Paulo Honório - encontrar o sentido oculto de sua vida - é explicitada pelo desejo de escrever o romance, de elaborá-lo como um projeto:

Tenciono contar a minha história. Difícil. (...) Aqui sentado à mesa da sala de jantar, fumando cachimbo e bebendo café, suspendo às vezes o trabalho moroso, olho a folhagem das laranjeiras que a noite enegrece, digo a mim mesmo que esta pena é um objeto pesado. Não estou acostumado a pensar. (RAMOS, 1995, p. 8).

Através da escritura, o personagem faz emergir o sentido da sua vida - ou a falta de sentido que a assinalou - encontrando-se ao final com seu destino trágico e solitário, revelando-se personagem problemático, detentor de diversas facetas. O Paulo Honório embrutecido e paralisado que, ao longo de sua trajetória, incorpora os hábitos do capitalista selvagem, apresenta sinais de mudança radical quando da execução de seu projeto de escrita, sinais que revelam a tomada de consciência de sua própria pequenez e de sua nulidade no mundo, além do fracasso de suas relações pessoais e afetivas. A realidade objetiva e exterior se desintegra e dissolve, dando lugar a uma realidade interior que desmantela a construção do caráter dominador do personagem, que sucumbe e entrega-se diante de sua derrota. $\mathrm{O}$ processo que consolida essa passagem é justamente o da escrita/reflexão, consumado pelo percurso errático e cambiante da memória:

Emoções indefiníveis me agitam - inquietação terrível, desejo doido de voltar, tagarelar novamente com Madalena, como fazíamos todos os dias, a esta hora. Saudade? Não, não é isto: é desespero, raiva, um peso enorme no coração.

Procuro recordar o que dizíamos. Impossível. As minhas palavras eram apenas palavras, e as dela tinham alguma coisa que não consigo exprimir. Para senti-las melhor, eu apagava as luzes, 
deixava que a sombra nos envolvesse até ficarmos dois vultos indistintos na escuridão (RAMOS, 1995, p. 101).

O papel estruturador da memória, ao qual nos referimos anteriormente, provoca mudanças na narrativa: o narrador, que detinha um ponto de vista seguro e objetivo ao contar sua história, começa a indagar-se com olhos duvidosos e interrogativos, apresentando uma primeira tomada de consciência de si mesmo. Passa-se, então, a reproduzir o vaguear da consciência, sua errância e desatino, processo inesperado na constituição de Paulo Honório como personagem, mimetizado pela nova linguagem subjetiva e pelo discurso memorialístico. A partir daqui, nada se sabe mais com certeza: "tudo não passa de conjectura, olhares que alguém dirige a outro, cujos enigmas não é capaz de solucionar" (AUERBACH, 1998, p. 479). Paulo Honório encerra esse "eu" e "outro", constantemente buscando reconhecer-se ao verdadeiramente olhar-se.

O romance, por detrás da aparente simplicidade de sua organização, concentra uma complexa estrutura que evidencia ora o olhar objetivo e prático, ora o ponto de vista subjetivo do personagem - veja-se a quebra assinalada pelo capítulo XIX, central na narrativa, em que o personagem revela perder o sentido do tempo, imergindo assim em seu tempo interior. Em decorrência da moderna representação do tempo interior (AUERBACH, 1998, p. 488), o narrador, encontrando-se ele próprio no objeto de análise, libera-se então como simples observador desse objeto, processo que predomina em boa parte da narrativa, e pode enfrentar seu passado: abandona a visão objetiva e determinista acerca dos fatos que permearam sua trajetória e pode, de fato, analisar sua história e não apenas contá-la. A tentativa de esquadrinhar uma realidade mais genuína, profunda e real faz entrever na narrativa uma mudança radical de foco e de tom: a interrupção do fluxo dominante, caracterizado pela linguagem prática, reflexo da personalidade de Paulo Honório, cede lugar a um relato carregado de reticências e interrogações, em que o tom pessoal e reflexivo permeia as linhas do texto com uma forte conotação subjetiva e melancólica. O texto mescla-se, assim, com a concorrência de múltiplas vozes que fazem com que a realidade tomada inicialmente como objeto apareça "sob uma iluminação cambiante e estratificada, ou para abandonar a posição da representação aparentemente objetiva, ou da representação puramente subjetiva, em favor de uma perspectiva mais rica" (AUERBACH, 1998, p. 491).

No romance Terra Sonâbula, o menino Kindzu, ao contar e rememorar sua história, também busca encontrar uma identidade - a identidade de seu povo, que é determinada por suas crenças, mitos, histórias, lendas - ao passo que também luta por sua sobrevivência. Os cadernos de Kindzu também consubstanciam o projeto memorialístico, empenhado em 
organizar as narrativas de seu povo, dotando-lhe de uma identidade histórica e mítica desfeita pelas guerras: "Quero pôr os tempos, em sua mansa ordem, conforme esperas e sofrências. Mas as lembranças desobedecem, entre a vontade de serem nada e o gosto de me roubarem do presente" (COUTO, 2007, p. 15). Assim como a Paulo Honório, o processo rememorante revela-se a Kindzu como percurso penoso e difícil em meio às aventurosas viagens, pois o ato de lembrar apresenta percalços a serem vencidos. A viagem mítica empreendida por Kindzu no mar traz-lhe numerosos sofrimentos, que no entanto se reconfiguram em ensinamentos e sabedoria, cujo maior resultado são os cadernos, herança da sociedade, "páginas da terra". Novamente a escrita presta-se a potencializar a trabalho da memória, pois por meio dela é que nos revelamos: "Escrever é propiciar a manifestação alheia, em que a nossa imagem se revela a nós mesmos" (CANDIDO, 1965, p. 90).

O menino Muidinga, ao participar desse processo de rememoração lendo os cadernos, cujos escritos começam a ocupar sua fantasia, consegue transmutar-se em Kindzu e continuar sua busca; dessa forma, a paisagem, até então "morta pela guerra", começa a ganhar prenúncio de verdes e a terra passa a abrigar futuros e felicidades; ganha uma nova identidade ao "brincar de ser Kindzu", ganha um pai e, portanto, uma história, uma origem, transformando-se em uma criança a nascer, em contraposição à criança carente de fantasia: "os escritos de Kindzu traziam ao jovem uma memória emprestada sobre esses impossíveis dias" (COUTO, 2007, p. 126). Kindzu, ao aventurar-se no mar, espaço da esperança e da mobilidade, identifica-se com a luta de Farida, adquirindo consciência de luta e, desta forma, encontrando sua própria identidade. Ambos os romances são, assim, narrativas de busca de uma identidade abalada que procura reconstruir-se pela ação da escrita e da constituição do discurso memorialístico. Como afirma Rejane Vecchia em Romance e Utopia, "Terra sonâmbula, primeiro romance de Mia Couto, narra a história de duas vidas em busca não só da sobrevivência, mas, dado o contexto da guerra, partem também em busca de uma identidade, confundida pela disputa do poder local" (VECCHIA, 2000, p. 107).

Assim, no romance coutiano, através dos sonhos que questionam a cruel realidade, podemos observar um modo de representação simbólica da luta de um povo e de uma nação. Os projetos dos personagens, que se unem por meio da ação recíproca entre escrita e leitura, transformam-se em "representações individuais e sociais que transcendem a situação imediata, inscrevendo-se no patrimônio do grupo" (VECCHIA, 2000, p. 118). Assim mesmo, representam

[...] um caminho trilhado às margens de uma esperança que, cultivada nas folhas do caderno, é capaz de trazer a expectativa do futuro. Os escritos significam cultivar a lucidez no presente e, 
ao preservar o passado e sua história, ambos apontam para um tempo futuro que nascerá das cinzas do presente. São essas anotações que permitem o resgate não só de Kindzu, mas de um indivíduo, sujeito de sua própria história e que se inscreve na história de uma nação (VECCHIA, 2000, p. 120).

O caminho de esperança, trilhado nas folhas do caderno, cujo principal motor é a recuperação das histórias do país e a manutenção de seu passado histórico, exemplifica o conceito de utopia desenvolvido por Ernest Bloch em seu Princípio Esperança. Duas das principais noções relacionadas ao conceito desenvolvido são a de sonho diurno e a de futuro.

Vejamos de que se tratam:

Bloch se esforça em demonstrar que essa atividade de "sonhar para a frente" está ligada a um "topos de conteúdo" preciso. [...] o sonho diurno será definido como um topos interior, como lugar de nascimento do desejo e da imaginação, como "guia" das "imagens do desejo" de algo que "ainda-não-é". E essas imagens têm a qualidade de antecipar um futuro onde predomina absolutamente, segundo Bloch, a utopia.

Quanto à noção de futuro, Bloch faz a distinção entre: 1) o futuro inautêntico e 2) o futuro autêntico. [...]; o "futuro autêntico" [...] é caracterizado pela presença de um elemento "excedente", permitindo a transformação de nossa imaginação utópica numa realidade humana em forma de "amanhã” (MÜNSTER, 1993, p. 26).

A leitura paralela das histórias de Muidinga e Kindzu, e a consequente reciprocidade de suas ações e esperanças fundada pela união que se opera entre os meninos por meio da tessitura e da leitura dos cadernos, faz-nos observar a relevância das noções de "sonho diurno" e "futuro", que fundamentam o princípio esperança e a construção de todo o romance. São possibilidades que se sustentam na prática real de determinadas ações que ajudam a entrever e construir uma perspectiva mais otimista, baseada na reconstrução da memória coletiva da sociedade moçambicana:

Com ele ganhara esta paixão das letras, escrevinhador de papéis como se neles pudessem despertar os tais feitiços que falava o velho Taímo. Mas esse era um mal até desejado. Falar bem, escrever muito bem e, sobretudo, contar ainda melhor. Eu devia receber essas experiências para um bom futuro (COUTO, 2007, p. 25).

Assim, o romance carrega-se de desejos e expectativas que dialogam com o devir, na esteira de uma escrita mais esperançosa e engajada: "Vou ajudar a acabar com a guerra. Me acredita, pai" (COUTO, 2007, p. 44). O sonho de liberdade, "sonhambulante", tecido em meio a uma perspectiva sempre "sonhatriz", conjuga-se em Kindzu e Muidinga, cujo “desejo de romper com os fatos da história" (VECCHIA, 2000, p. 118) por meio da imaginação e da memória, da escrita e da leitura, aponta para a construção de um futuro que não seja permeado somente pela dor, em que podemos ver a terra, após a chuva, "arco-iriscando": "O sonho é o olho da vida"; "Só recordo esta inundação enquanto durmo. Como as tantas outras lembranças que só me chegam em sonho"; "Talvez, quem sabe, cumprisse o que sempre fora: sonhador 
de lembranças, inventor de verdades. Um sonâmbulo passeando entre o fogo. Um sonâmbulo como a terra em que nascera" (COUTO, 2007, p. 19;21;107, grifos nossos).

Voltando-nos à comparação com o romance São Bernardo, contudo, veremos que a perspectiva otimista e esperançosa que se entretece nas linhas do texto coutiano não se verifica no romance brasileiro. Há uma noção imperativa do trágico que caracteriza o romance e a personagem principal, para quem não há redenção possível. O esforço empreendido pela escritura de seu romance, amarga confissão de sua falha pessoal, não lhe traz qualquer perspectiva de entrever a felicidade e um futuro autêntico. Assim, se os romances aqui analisados se aproximam por conterem a perspectiva da escrita e da rememoração como busca de um auto-conhecimento que possa efetivar a reconstrução identitária, distanciam-se na maneira como empreendem essa tarefa.

Uma das diferenças centrais observadas quando da leitura dos romances é a posição do narrador, se o entendemos a partir dos tipos fundamentais tal como elaborados por Benjamin em “O Narrador", presente no primeiro volume de Obras escolhidas. Identificando-se com o tipo do narrador viajante, que coleta e intercambia experiências, os personagens narradores de Terra Sonâmbula, ora Kindzu, ora Muidinga, ora Tuahir, carregam consigo a arte de compartilhar histórias, de construir a história de seu povo ao entrecruzar a esfera mítica e a esfera histórica, o que assegura à narrativa a sua dimensão miraculosa e fantástica, ao lado da verídica e cruel realidade da guerra civil, conferindo maior amplitude ao narrado. O leitor pode assim interpretar a história de sobrevivência dos moçambicanos com maior liberdade do que se o autor a tivesse contado somente a partir de sua dimensão histórica.

Há também, em Terra Sonâmbula, o compartilhar da experiência da morte; como afirma Benjamin, "é no momento da morte que o saber e a sabedoria do homem e sobretudo sua existência vivida - e é dessa substância que são feitas as histórias - assumem pela primeira vez uma forma transmissíveis" (BENJAMIN, 1994, p. 207). Nesse momento, então, em que a sabedoria e o legado das estórias é transmitido, para que se perpetue a prática social do narrar, ficam asseguradas a História e a identidade de um povo. É essa justamente a função de Muidinga: ao transmutar-se em Kindzu, e ao ganhar a identidade por ele conferida, Muidinga pode perpetuar a prática narrativa, que restaura a identidade deste povo abalada pela guerra. As estórias contadas por Kindzu são todas transmitidas a Muidinga, que agora pode recontálas. A morte, então, não abala as experiências vividas, porque a trajetória do contador de estórias já se incorporou à trajetória dos demais, fazendo de sua experiência uma experiência coletiva. Novamente retomando Benjamin, a experiência dos grandes narradores "é a imagem de uma experiência coletiva, para qual mesmo o mais profundo choque da experiência 
individual, a morte, não representa nem um escândalo nem um impedimento" (BENJAMIN, 1994, p. 215).

A narrativa abre-se, assim, novamente, à possibilidade de realização de uma utopia libertária, em que a morte é apenas uma passagem e não um impedimento para a sua efetivação. Assim mesmo, a consolidação do legado de Kindzu assegura-se por meio de sua escrita, e por meio da leitura de Muidinga, que adquire todo o seu conhecimento e reveste-se de sua sabedoria.

Benjamin também pontua a diferença entre o narrador clássico - o narrador da narrativa oral - e o narrador do romance moderno, que traz a ameaça da morte à narrativa: enquanto o narrador da tradição oral se constitui pelo intercâmbio de experiências, incorporando às suas experiências aquelas ouvidas e vice-versa, o narrador do romance se isola, e segrega-se.

Em Terra Sonâmbula, se a troca de experiências e a transmissão da sabedoria é fundamental para o surgimento da identidade do persongem Muidinga, e em maior medida, da própria constituição da identidade do povo moçambicano, em São Bernardo, o narrador é aquele que isolado e segregado em sua única realidade é incapaz de dar e receber conselhos, e assim, de intercambiar sabedoria, como elabora Benjamin acerca do narrador do romance moderno. A incapacidade de Paulo Honório de olhar ao redor e compartilhar das experiências de Madalena, de ouvir os seus empregados, de permitir-lhes a dimensão do diálogo, o embrutece, o paralisa, o torna incapaz de conciliar-se com sua própria linguagem. O homem do romance moderno, como descreve Benjamin, é aquele que, praticamente mudo, analisa a existência humana com perplexidade, e que, encerrado em sua solidão, não consegue e não pode mais falar de suas preocupações, temores, e nem pode, assim, receber conselhos. Ao passo que o romance moderno se fecha e tem uma dimensão finita a partir do seu término, ao finalizar a busca do entendimento daquela trajetória vivida, a dimensão da narrativa oral incorporada ao romance Terra Sonâmbula lhe confere uma eternidade e durabilidade que o identificam com a própria (re)construção da identidade de um Moçambique devastado pela guerra colonial e pós-colonial.

Essa imagem da utopia que se delineia no romance de Mia Couto, através da trajetória do menino Muidinga, que ao unir-se a Kindzu pelo laço dos cadernos lidos "pode romper com o véu do mundo vivido e traduzir seus sonhos para a construção de seu futuro autêntico" (VECCHIA, 2000, p. 118), não se vê, como afirmamos, em São Bernardo. Isto é: a escrita, neste romance, não se relaciona diretamente à construção de uma utopia - constrói-se, com efeito, como um projeto de busca de uma verdade mais profunda, mas esta não necessariamente lhe traz uma redenção. Concilia-se com a linguagem, porque é a partir dela 
que Paulo Honório é capaz de encontrar uma significação para a sua trajetória; é a partir da própria linguagem que Paulo Honório pode entender que esta não fazia parte de sua vida (afinal, nem a carta de Madalena anunciando um suicídio Paulo Honório é capaz de entender); no entanto, essa conciliação não o redime - só lhe traz uma certeza de um destino amargo e solitário.

Já no romance moçambicano, o desejo de romper com a realidade vivida e com os fatos da história se esboça através de uma operação que é bastante comum na literatura brasileira: "uma espécie de estratégia destinada a contornar os aspectos mais trágicos da condição humana" (LOURENÇO, 2001, p. 197), que o autor, em A Nau de Ícaro, elabora como a "rasura do trágico". Como afirma o crítico português acerca da literatura brasileira,

Todos esses heróis vivem os diversos horrores da condição humana em termos da mais luminosa expressão brasileira, de uma precisão quase hiper-realista, mas vivem-na numa espécie de lugar mágico, fora do mundo, [...]. É a grande translação do trágico brasileiro, a sua transfiguração e transcensão mágicas (LOURENÇO, 2001, p. 204).

Esse reflexo quase generalizado da literatura brasileira surge justamente num momento em que se buscava o reforço da consciência propriamente brasileira. Através da esfera do sonho, os personagens de Guimarães Rosa, por exemplo, conseguem realizar uma translação do trágico, em que se dá uma transfiguração mágica. Segundo o crítico,

A estrutura cultural eufórica que caracteriza o modernismo brasileiro [...] vai constituir-se como uma segunda natureza do Brasil. E a partir de então a imagem de marca, o mito de que precisava para exprimir cabalmente o novo sentido de força, de existência, de progresso, um país que mudava profundamente e rejeitava com a água do banho a criança colonial e escrava que fora durante séculos.

Este novo mecanismo do Brasil para si mesmo [...] condicionará a forma do espírito e da cultura brasileiros, envolvendo na sua pulsão positiva e otimista as visões mais cruas ou dolorosas da vida nacional nos seus aspectos históricos ou individuais. Por mais realista e crítica que seja a literatura brasileira dos anos 30 e 40, a preocupação pelo Brasil que ela reflete raramente se traduz em visão trágica da existência, embora, descritivamente, integre a tragédia objetiva, o escândalo humano e social [...]. (LOURENÇO, 2001, p. 201)

Na análise do romance Terra sonâmbula, tendo em conta a perspectiva da quase "ausência" da visão puramente trágica que caracteriza a literatura brasileira modernista, como observado por Lourenço, observamos um trânsito cultural que caracteriza fortemente as literaturas de língua portuguesa. O personagem Muidinga, ao situar-se na esfera mítica e onírica, acessada através dos cadernos de Kindzu, consegue libertar-se da prisão em que vive - a realidade de sobrevivente/fugitivo - e criar uma nova identidade e uma nova vida, na qual encontra mais sentido. A rasura do trágico, como reflexo da literatura brasileira, é justamente uma das linhas que se contorna em Terra Sonâmbula, o que coloca ambas as literaturas dentro de um sistema de intercâmbios solidários, já que imersas em esferas culturais semelhantes, 
por compartilharem determinadas experiências históricas. Ademais, essa estratégia também elaborada por Mia Couto está em consonância com o projeto cultural do autor de reelaborar a identidade da nação moçambicana, assim como se vê no projeto cultural modernista brasileiro. Ambas as nações, tendo sofrido o choque da colonização, precisam reestruturar-se psiquicamente com vistas a elaborar sua "nova" identidade, perdida ou abalada em face da indelével marca da colonização.

Assim posto, notamos estar diante de um conjunto de textos que estabelecem diversas redes de comunicação e pontos de articulação. O conceito de hibridismo cultural sugere matérias em movimento, de "caráter instável", em "seu constante vir-a-ser" (ABDALA Jr., 2002, p. 103) e se verifica a partir da abordagem em perspectiva de diversos textos em língua portuguesa, revelando pontos de contato que caracterizam matérias culturais híbridas; no entanto, como cada texto se insere a partir de seu lócus enunciativo, revelando distintas situações históricas - apesar de seus pontos de contato, como a situação de colonização vivida pelos países de língua portuguesa, e sua subsequente busca por uma reafirmação identitária e nacional, por meio da renovação da língua e da literatura - a obra literária também afirma sua autonomia específica. Igualmente verifica-se que os pontos de contato estabelecidos entre essas literaturas, pela adoção de mecanismos semelhantes e procedimentos que sugerem trocas e diálogos, desvela um ambiente cultural solidário que aponta para "fronteiras de contato e compartilhamento" (ABDALA Jr., 2002, p. 38), através de um sentimento de parentesco. Dessa forma, verificamos que "as precondições para a adoção são a necessidade de importação ideológica e a existência de tendências mais ou menos paralelas na sociedade e na literatura adotada" (ZHIRMUNSKY, 1994, p. 207). Diríamos que, no caso das literaturas que estamos comparando, a "adoção", levada em conta sem contornos pejorativos, de determinados aspectos da literatura brasileira ocorre precisamente porque se identificam esses paralelismos entre as sociedades e as literaturas.

Curiosamente, se refletimos acerca dessa estratégia marcadamente brasileira no que diz respeito ao romance São Bernardo, no entanto, veremos que não há qualquer esforço em contornar a realidade trágica: muito pelo contrário, o projeto de Paulo Honório se identifica justamente com a busca de uma compreensão que inevitavelmente o levaria ao sofrimento. Encontrar-se com sua própria natureza embrutecida e assumi-la é parte do processo de maturidade do personagem, que o faz tornar-se múltiplo e problemático. Esta é sua busca, sua missão, consolidada pelo seu projeto de escritura do romance. Constituindo-se como outra grande diferença com o romance de Mia Couto, 
É precisamente no autor mais "ortodoxo" (nessa época) que encontramos uma das raras visões realmente trágicas do romance brasileiro moderno. Referimo-nos não só ao autor de Angústia, mas do tão machadiano São Bernardo, livro de um pessimismo intenso [...] (LOURENÇO, 2001, p. 202).

Todavia, para além de convergências ou divergências entre as obras no que diz respeito à perspectiva otimista e esperançosa que se esboça no romance de Mia Couto e ao pessimismo trágico subjacente ao romance brasileiro, outras aproximações são possíveis entre os romances. Com efeito, a partir do foco no sujeito que se põe a escrever e a deixar um legado, pode-se observar que ambos dizem respeito a um aspecto inerente ao ser humano, que caracteriza sua busca: a de auto-conhecimento e de conjunção com uma verdade mais ampla, em São Bernardo, e a de (re)construção de uma identidade, possível através da escrita/leitura/memória de um povo, em Terra Sonâmbula. Ambas as narrativas, assim, tratam de conflitos que são universais e próprios do ser humano.

As histórias de Paulo Honório e de Muidinga/Kindzu não se particularizam em seus tempos, mas se universalizam e se tornam legado da humanidade. Segundo Antonio Candido, em Literatura e Sociedade, a literatura detém uma função, que para além de suas funções mais facilmente identificáveis - a ideológica e a social -

[...] deriva da elaboração de um sistema simbólico, que transmite certa visão de mundo por meio de instrumentos expressivos adequados. Ela exprime representações individuais e sociais que transcendem a situação imediata, inscrevendo-se no patrimônio do grupo (CANDIDO, 1965 , p. 54).

Identificamos em ambas as obras esta força expressiva de sua função total, que definitivamente inscrevem São Bernardo e Terra Sonâmbula em um patrimônio da humanidade, para além de suas épocas e panos de fundo históricos.

Mais claramente em Terra Sonâmbula, podendo ser tomado como um projeto de reconstrução da nação moçambicana (libertação de Junhito, o menino que simboliza a independência), a experiência coletiva da qual a obra é depositária é identificada à luta de um povo por sua possibilidade de libertação, não somente literal, mas mágica, capaz de, através da esfera mítica e onírica, ascender a um novo mundo. Segundo Frantz Fanon, em Condenados da Terra,

[...] a experiência individual, porque é nacional, elo da existência nacional, deixa de ser individual, limitada, estreita e pode desaguar na verdade da nação e do mundo. Assim como na fase de luta cada combatente sustentava a nação na ponta do braço, da mesma forma, durante a fase de construção nacional, cada cidadão deve continuar em sua ação concreta de todos os dias a associar-se ao conjunto da nação, a encarnar a verdade constantemente dialética da nação, a querer aqui e agora o triunfo do homem total (FANON, 1968, p. 164). 
É justamente o que ocorre com as experiências de Kindzu e Muidinga: aliam-se ao conjunto total da nação e à trajetória possível da nação moçambicana ao empreender sua luta pela liberdade, mais que todas, a moral. O final do romance concretiza essa passagem - o menino Kindzu, ao morrer e deixar seus cadernos como legado, afirma:

Deixo cair ali a mala onde trago os cadernos. Uma voz interior me pede para que não pare. É a voz de meu pai que me dá força. [...]. Mais adiante segue um miúdo com passo lento. Nas suas mãos estão papéis que me parecem familiares. Me aproximo e, com sobresslato, confirmo: são os meus cadernos. [...]. E o menino estremece com se nascesse por uma segunda vez. De sua mão tombam os cadernos. Movidas por um vento que nascia não do ar mas do próprio chão, as folhas se espalham pela estrada. Então, as letras, uma por uma, se vão convertendo em grãos de areia e, aos poucos, todos meus escritos se vão transformando em páginas da terra (COUTO, 2007, p. 204).

É essa perspectiva de convidar à ação e fundar a esperança que aponta, novamente, Fanon. Pela transmutação que se opera entre Muidinga e Kindzu e, após a transmissão do legado do qual os cadernos são depositários, podemos perceber a real função da escrita que se tece na obra:

O homem colonizado que escreve para seu povo deve, quando utiliza o passado, fazê-lo com o propósito de abrir o futuro, convidar à ação, fundar a esperança. Mas para garantir a esperança, para lhe dar densidade, é preciso participar da ação, engajar-se de corpo e alma no combate nacional (FANON, 1964, p. 168).

A esperança fundada e o convite ao futuro são, certamente, o projeto e o legado do menino Kindzu, ao converter-se em Naparama, lutando contra os fazedores de guerra, ao salvar seu irmão Junhito, o símbolo da independência moçambicana e ao buscar Gaspar/Muidinga, o detentor de seus cadernos, aquele responsável pela propagação da cultura e da identidade da nação.

São Bernardo, por sua vez, encarnando uma visão realmente trágica da condição humana, não deixa de elaborar o herói trágico que empreende uma valente e honesta busca ao querer dar à sua vida aquele sentido ignorado, recalcado na linguagem embrutecida, esquecida, repelida. É uma busca de todo e qualquer ser humano quando se encontra diante da mais crua realidade e deve enfrentar seu passado renegado. A rememoração, então, vem a serviço de um projeto do sujeito que se propõe a investigar as causas subjetivas de sua infelicidade, descobrindo-as, muito embora, nos fatos mais objetivos de sua história. O romance elabora, perfeitamente, aquilo que Antonio Candido elevaria como característica central do romance moderno brasileiro. A partir da tendência geral para a análise que se desenhou na segunda fase do Modernismo brasileiro, classificada entre os anos de 1922 e 1945, em que os autores investiam em buscar explicações, tentar sínteses e esquadrinhar o seu tempo, o crítico localiza como mais importante o decênio de 1930. No romance desse 
decênio, o mais característico do período é a "preponderância do problema sobre o personagem. É a sua força e a sua fraqueza" (CANDIDO, 2008, p. 147). Mais uma vez aparecendo em textos ontológicos sobre o Modernismo, São Bernardo figura entre as obras universais a partir do seguinte comentário:

\begin{abstract}
A humanidade singular do protagonista domina os fatores do enredo: meio social, paisagem, problema político. Mas, ao mesmo tempo, tal limitação determina o importantíssimo caráter do movimento dessa fase do romance, que aparece como instrumento de pesquisa humana e social, no centro de um dos maiores sopros de radicalismo da nossa história (CANDIDO, 2008, p. 148).
\end{abstract}

Ambas as obras, então, de maneiras diferentes, expressivas em sua função total, se inscrevem no patrimônio cultural de suas nações, identificáveis como projetos culturais distintos, em vista de suas contraposições no que diz respeito às fulgurações da utopia e da perspectica trágica, embora não marcadamente pessimista, já que se delineia na obra uma verdadeira transmutação da personagem.

Distintas formas de pertencer ao patrimônio cultural, distintos pontos de vistas que apontam, ainda assim, para novas articulações comunitárias em um novo aspecto: o papel do intelectual. Mia Couto e Graciliano Ramos procuram o caminho mais difícil quanto à escolha do intelectual, como coloca Said (2005, p. 46), ao revelarem-se interessados em abalar a estabilidade da norma dominante, considerando-a como um estado de emergência que ameaça a sociedade. Os escritores procuram, assim, contestar e questionar os sistemas vigentes, buscando outras formas de revelar o encoberto, por meio dos projetos de escrita encerrados em suas obras, potencializados pelo sujeito rememorante. A escrita pode e deve revelar questões embaraçosas e concernentes a problemas universais, tais como a construção da identidade: encontramos esse intuito no projeto dos escritores que se espraiam também para os próprios personagens - a escrita dentro da escrita - pelo que se afirma a universalidade de suas obras e sua inegável inscrição no patrimônio cultural das nações. Como afirma Said (2005, p. 26), “o intelectual age com base em princípios universais” e seu objetivo é "promover a liberdade humana e o conhecimento". (SAID, 2005, p. 31).

Assim posto, finalizamos essa trajetória empreendida pela memória de tão significativos personagens novamente ressaltando que, a despeito da utopia carregada de sonhos diurnos traçada na narrativa moçambicana, e, por outro lado, da pungente visão trágica esboçada pela pena de Graciliano, podemos observar alguns trânsitos culturais que colocam as obras em uma sintonia, tendo em conta a perspectiva da necessidade da memória e da fundação de uma narrativa da memória que se instaura no século XX. Não obstante os sonhos diurnos de Kindzu e Muidinga e os amargos devaneios de Paulo Honório, a literatura se 
afirma como espaço privilegiado para sonhar, rememorar e revelar o encoberto, na tentativa de, ao menos, "acender as luzes e reparar a escuridão" (COUTO, 2007, p. 198).

\section{Referências}

ABDALA Jr., Benjamin. Fronteiras Múltiplas, identidades plurais. Um ensaio sobre mestiçagem e hibridismo cultural. São Paulo: SENAC, 2002.

AUERBACH, Erich. "A Meia Marrom”. In: literatura ocidental. São Paulo: Perspectiva, 1976.

Mimesis: A representação da realidade na

BENJAMIN, Walter. "O Narrador". In: 3.ed. São Paulo: Brasiliense, 1987. Obras escolhidas, I: Magia, técnica, arte e política.

CANDIDO, Antonio. Literatura e sociedade. 10ª ed. Rio de Janeiro: Ouro sobre Azul, 2008.

CARVALHAL Tânia \& COUTINHO, Eduardo (Orgs.). ZHIRMUNSKY, Victor. Sobre o estudo da literatura comparada. In: Literatura comparada: textos fundadores. Rio de Janeiro: Rocco, 1994.

COUTO, Mia. Terra Sonâmbula. São Paulo: Companhia das Letras, 2007.

FANON, Franz. Os condenados da terra. Rio de Janeiro: Civilização brasileira, 1979.

LOURENÇO, Eduardo. "Da literatura brasileira como rasura do trágico". In: A nau de Ícaro. São Paulo: Companhia das Letras, 2001.

MÜNSTER, Arno. "Ernst Bloch e o novo espírito utópico". In: Ernst Bloch - Filosofia da práxis e utopia concreta. São Paulo: Editora Unesp, 1993.

RAMOS, Graciliano. São Bernardo. 64.ed. Rio de Janeiro: Record, 1995.

SAID, Edward. Representações do intelectual. Trad. Milton Hatoum. São Paulo: Companhia das Letras, 2005.

VECCHIA, Rejane. Romance e utopia: Quarup de Antonio Callado, Terra Sonâmbula de Mia Couto e Todos os nomes de José Saramago. 2000. Dissertação (Doutorado em Letras) - Faculdade de Filosofia, Letras e Ciências Humanas, Universidade de São Paulo, São Paulo, 2000. 